\title{
ESTIMATING THE INHALED DOSE OF POLLUTANTS DURING INDOOR PHYSICAL ACTIVITY
}

\author{
C.A. Ramos ${ }^{1,3}$, J.F. Reis ${ }^{2}$, T. Almeida ${ }^{2}$, F. Alves ${ }^{2}$, H.T. Wolterbeek ${ }^{3}$, S.M. Almeida ${ }^{1}$
}

${ }^{1}$ Centro de Ciências e Tecnologias Nucleares, Instituto Superior Técnico, Universidade de Lisboa, Estrada Nacional 10, Km 139.7, 2695-066 Bobadela LRS, Portugal

${ }^{2}$ CIPER, Faculdade de Motricidade Humana, Universidade de Lisboa, Lisboa, Portugal

${ }^{3}$ Faculty of Applied Sciences, Department of Radiation, Radionuclides and Reactors, Technical University of Delft, Delft, The Netherlands

*corresponding author: carla.ramos@ctn.ist.utl.pt

Keywords: dose, inhalation, indoor air, physical activity, fitness centers, pollutants

Background: It is undeniable that many benefits come from physical activity. People exercise in fitness centers to improve their health and well-being, prevent disease and to increase physical attractiveness. However, these facilities join conditions that cause poor indoor air quality. Moreover, increased inhalation rates during exercise have influence on inhaled doses of air pollution. Objectives: This study aims to calculate the inhaled dose of air pollutants during exercise, by estimating minute ventilation of participants and measuring air pollutant concentrations in fitness centers. Methods: Firstly, the 20 participants performed an incremental test on a treadmill, where heart rate and minute ventilation were measured simultaneously to develop individual exponential regression equations. Secondly, heart rate was measured during fitness classes and minute ventilation was estimated based on the calculated regression coefficients. Finally, the inhaled dose of air pollutants was calculated using the estimated minute ventilation and the concentrations of the pollutants measured in a monitoring program performed in 63 fitness classes. Results: Estimated inhaled doses were higher in aerobic classes than in holistic classes. The main difference was registered for $\mathrm{PM}_{10}$ inhaled dose that presented an average ratio between aerobic and holistic classes greater than four. Minute ventilation and $\mathrm{PM}_{10}$ concentrations in aerobic classes were, on average, 2.0 times higher than in holistic classes. Results showed that inhalation of pollutants is increased during heavy exercise, demonstrating the need to maintain high indoor air quality in fitness centers. CONCLUSIONS: This study illustrates the importance of inclusion minute ventilation data when comparing inhaled doses of air pollution between different population groups. This work 
has estimated for the first time the minute ventilation for different fitness classes. Also constitutes an important contribution for the assessment of inhaled dose in future studies to be performed in fitness centers.

\section{INTRODUCTION}

Approximately 3.2 million deaths each year are attributable to insufficient physical activity and it is the fourth leading risk factor for death worldwide (WHO, 2014). The benefits that come from physical activity are indubitable (Warburton et al., 2006) and contribute to improve people's health, reducing cardiovascular diseases (Myers, 2003; Patel et al., 2013) and diabetes (Brown, et al., 2014; Weisser, 2014), preventing several types of cancer and recovering from it (Foucaut, 2014; Keimling et al., 2014; Behrens et al., 2014; Gotte et al., 2013; Gonçalves et al., 2014; Buffart et al., 2014), improving musculoskeletal status and disability (Laskowski and Lexell, 2012) and finally potentiating physical attractiveness, well-being (Duda et al., 2014) and social experiences (Pila et al., 2014). The rates of physical activity are different across countries and regions, gender, age and socioeconomic status. According to the Eurobarometer Sport and Physical Activity Report (2013), citizens in the northern part of the EU are more physically active than the southern, with the lowest levels of participation found clustered in the southern EU Member States. Men are more likely to exercise or play sports than women, with the amount of regular activity tending to decrease with age.

The practice of sport in fitness centers in 2009 registered a slight increase in the number of memberships of health or fitness centers (Eurobarometer, 2013). Fitness centers join specific characteristics that can affect indoor air quality (IAQ) and trained or recreational athletes can be at risk when they exercise in polluted environments due the fact that 1) the increases of the minute ventilation increases proportionally to the quantity of inhaled pollutants; 2) most of the air is inhaled through the mouth, bypassing the normal nasal mechanisms for filtration of large particles and 3) the increased airflow velocity carries gaseous pollutants deeper into the respiratory tract (Carlisle and Sharp, 2001). An IAQ monitoring program performed in eleven fitness centers from Lisbon, Portugal, indicated concerning levels of volatile organic compounds (VOC), formaldehyde $\left(\mathrm{CH}_{2} \mathrm{O}\right)$, carbon dioxide $\left(\mathrm{CO}_{2}\right)$ and particulate matter (PM) (Ramos et al., 2014). Moreover, toxigenic fungal species were found present within the same fitness centers (Ramos et al., 2015). PM has also been identified as a concerning pollutant in fitness centers by Braniš and Safranek (2011) and Buonanno et al. (2013).

Data on IAQ in fitness centers demonstrate the importance of studying exposure to pollutants during physical activity in order to minimize adverse health effects and potentiate the benefits of 
physical activity. Moreover, there is an increasing number of studies on exposure to air pollutants in different indoor air spaces: elderly care centers (Almeida-Silva et al, 2014a,b; Viegas et al., 2014), offices (Almeida et al., 2013), schools (Pegas et al, 2010; Canha et al., 2011, 2014) and fitness centers (Ramos et al., 2014). However, only few of them have taken into account that sport practitioners have an increased minute ventilation (VE) compared to elders, office workers or children influencing their inhaled dose of air pollutants (Almeida-Silva et al., 2015). For increased health benefits, adults should practice moderate-intensity aerobic physical activity to 300 minutes/week (WHO, 2010). This represents 5 hours/week and with this information, the time spent during exercise reveals great importance to the relative daily dose, due to the increased VE் in this activity than in others that take more time (e.g. sleep) (Dons et al. 2011).

The study of the interaction between person and pollutant involves several steps. The inhaled dose is one of the principal steps in the chain of events since dose received by an individual directly influences the impacts on health. This work joined environmental researchers and exercise physiologists to assess the inhaled dose of pollutants during fitness center's classes.

\section{METHODS}

The inhalation dose of pollutants during the fitness classes was estimated by using the methodology described in Figure 1.

\subsection{Determination of $\mathbf{V} \dot{\mathbf{E}}$ during fitness classes}

Since VE் has never been measured before for fitness class users, this work estimated VE் for aerobic and holistic classes that represent the majority of the programs offered in fitness centers. $V \dot{E}$ is difficult to measure in field studies due to some constraints such as discomfort for the user and the need for an elevated number of instruments to perform the evaluation of a representative number of individuals. However, VÉ can be estimated by measuring HR in fitness classes because HR is easily measured and is a good predictor of VE் (Mermier et al., 1993; Zuurbier et al., 2009). Once HR is mainly influenced by oxygen consumption and the correlation between oxygen consumption and VE் is high, HR and VE் are expected to be strongly associated.

\subsubsection{Studied Population}

Ten men and ten women participated in this study and signed a free and informed agreement. A questionnaire was applied to the participants about their physical status and healthy behaviours (smoking status, hours of physical activity per week, cardiac and respiratory diseases, orthopedic problems). On test days, the subjects were instructed to report to the laboratory or 
the fitness center in a rested state, having completed no strenuous exercise or consumed alcohol within the previous $24 \mathrm{~h}$, and having abstained from food and caffeine for the preceding $3 \mathrm{~h}$.

Table 1 presents the descriptive statistics of the studied population. The age of the volunteers varied between 18 and 38 years old, representative of principal users of fitness centers. All the subjects were physically active, but not involved in an exercise training program at the time of data collection. The weekly exercise volume is as stated in Table 1 . The average body mass index (BMI) and weight are similar to the average Portuguese BMI.

\subsubsection{Estimation of the association between $V \dot{E}$ and HR in laboratory}

$\mathrm{VE}$ levels of the participants were estimated using HR measurements, because direct measurements of VE் are not recommended as it would influence VE். Therefore, participants performed an incremental test on the treadmill in order to establish the individual relation between HR and VE் during the exercise. After a warm-up period of 3 minutes at $5 \mathrm{~km} / \mathrm{h}$, the subjects performed an incremental test with $1 \mathrm{~km} / \mathrm{h}$ increments each minute, until exhaustion. Throughout the test, the respiratory and pulmonary gas-exchange variables were measured using a breath-by-breath portable gas analyzer (Cortex Metamax 3B, Leipzig, Germany). Before each test, the $\mathrm{O}_{2}$ and $\mathrm{CO}_{2}$ analysis systems were calibrated in accordance with manufacturer's guidelines against known concentrations of cylinder gases (15\% oxygen, $5 \%$ carbon dioxide) while the turbine flowmeter was calibrated using a 3-1 syringe. HR was also monitored throughout the tests (Polar, Kempele, Finland). Breath-by-breath $\mathrm{VO}_{2}$ and $\mathrm{HR}$ data were averaged using $10 \mathrm{sec}$ bins. After the simultaneous measurement of $\mathrm{VE}$ and $\mathrm{HR}$ in the laboratory, exponential regression equations between these parameters were calculated. The effect of gender, age and BMI on individual slopes and intercepts was analyzed.

\subsubsection{Estimation of the $V \dot{E}$ for the holistic and aerobic fitness classes}

The participants performed, in group, two fitness classes - a holistic class and an aerobic class of 45 minutes each, guided by a professional fitness instructor. The duration and types of classes were chosen for being representative of classes usually found at any fitness center. Both were composed of 3 stages: 1) starting warm-up period, 2) main conditioning period and, 3) final period of active recovery and, for the holistic class, meditation.

The holistic class is inspired by Pilates, Yoga and Tai Chi movements where the training of flexibility and strength were the primary goals. The types of exercises practiced were related to balance, stability and flexibility with a series of stretches and strength poses that provides a quiet and harmonious state of mind. The aerobic class is characterized by jumps, fast and vigorous movements of legs and arms, and other body weight strength exercises. The participants perform cardiovascular and core strength training, providing an effort much more demanding than in the holistic class. 
During the fitness classes HR was recorded with a heart rate monitor from Polar Team ${ }^{2}$ Pro (Polar, Kempele, Finland). The transmitter in the waistband recorded the data and communicated with the Polar Team ${ }^{2}$ Base Station (Polar, Kempele, Finland), which allowed the visualization of the data in real time. Immediately after each class, the subjects classified it with the Borg Scale Perceived Exertion Rate (RPE) from 1 (very easy) to 10 (maximal exertion) (Foster et al., 2001). The recorded HR were calculated into VE் levels using the regression coefficients.

\subsection{IAQ monitoring program}

In 2012, a monitoring program was carried out during 63 fitness classes in Lisbon. For this, a Graywolf (IQ-610 probe, WolfSense Solutions, USA) was used to measure $\mathrm{CO}_{2}, \mathrm{CO}, \mathrm{COV}, \mathrm{O}_{3}$ temperature and relative humidity, a Lighthouse Handheld (3016 IAQ, Lighthouse Solutions, USA) assessed $\mathrm{PM}_{10}, \mathrm{PM}_{5}, \mathrm{PM}_{2.5}, \mathrm{PM} 1$ and $\mathrm{PM}_{0.5}$, and a Formaldemeter (htV-M, PPM Technology, UK) measured $\mathrm{CH}_{2} \mathrm{O}$. The equipment was positioned at $1.20 \mathrm{~m}$ above ground and $1.50 \mathrm{~m}$ away from the walls in order to avoid the influence on airborne particle dispersion (Jin et al., 2013; Holmberg and Li, 1998). Data was logged in 1 minute intervals. All the equipment was calibrated according the manufacturer specifications. A correction factor $(\beta)$ was applied to the PM indoor concentrations (obtained by the Lighthouse Handheld) and is already described in Ramos et al. (2014).

\subsection{Statistical analysis}

Origin $8.0^{\circledR}$ was used to compute the individuals' regression equations. The statistical tests were performed with Statistica $12^{\circledR}$ software.

\section{RESULTS}

\subsection{Estimation of the $V \dot{\mathbf{E}}$ in fitness classes}

Exponential regression equations between HR and VE were calculated for the 20 volunteers. Regression lines of all individuals discriminated by gender are presented in Figure 2. In Table 2 are presented the distribution of the regression coefficients for men, women and for the total group. The correlation between HR and VE் was high (mean $\left.\mathrm{r}^{2}=0.90\right)$ suggesting, as expected, that HR is a good predictor of VE.

Zuurbier et al. (2009) stated that the use of a general equation results in a good prediction of the mean VE். Although the author emphasized that, if the focus of the study is at the individual level, an overall equation of the whole group may result in substantial differences in estimated 
$\mathrm{VE}$ at the individual level. In the same way, Mermier et al. (1993) indicated that it is necessary to calculate individual regression equations due to the individual variability among HR and VE். Results showed small differences in slopes and intercepts between individuals of the same gender and lower intercept in women than in men.

During the fitness classes, HR of the volunteers was measured in order to estimate the VE using the individual relation between HR and VE derived from the laboratory test. Figure 3 presents the HR in the fitness classes. In both classes men presented lower HR $\left(98 \pm 17 \mathrm{~min}^{-1}\right.$ in the holistic and $120 \pm 17 \mathrm{~min}^{-1}$ in the aerobic) than women $\left(106 \pm 20 \mathrm{~min}^{-1}\right.$ in the holistic and $146 \pm 21$ $\min ^{-1}$ in the aerobic). Table 2 presents the HR measured in both fitness classes and the estimated VE். The results are displayed by genders and for each individual.

In the holistic class that involves stages of localized force, stability, balance and breath control an average VE் of $27 \pm 8 \mathrm{~L} / \mathrm{min}$ for men and $25 \pm 10 \mathrm{~L} / \mathrm{min}$ for women were estimated. In the aerobic class, characterized by intense cardio and aerobic movements, the average VE was $37 \pm 12 \mathrm{~L} / \mathrm{min}$ for men and $57 \pm 20 \mathrm{~L} / \mathrm{min}$ for women. The Mann Whitney test showed no statistical differences between genders for the VE $(p=1, C I=95 \%)$. Significant differences were found between the holistic and the aerobic fitness classes for women (Wilcoxon matched pairs test, $p=0.0005, \mathrm{CI}=95 \%$ ). RPE is a subjective way of measuring physical activity intensity level, based on the personal experiences on physical sensations during physical activity, including increased HR, breathing rate, sweating and muscle fatigue (CDC, 2011). Men evaluated the holistic class as moderate level (2.9) while women considerate it as somewhat hard (4.5). Both genders classified the aerobic class as hard (5.4 for men and 6.0 for women).

\subsection{Indoor air quality assessment}

A total of 63 fitness classes were classified according to their typology as aerobic or holistic. The aerobic class category included all fitness classes which stimulate power, strength, vigorous and fast movements; cycling classes were excluded from this collection. Holistic classes included all classes that comprise meditation, stability and flexibility movements. IAQ was assessed in the 63 fitness classes, with pollutants' concentrations measured during the activities presented in Table 3.

Concentrations measured in the fitness classes were compared with the Portuguese legislation, Portaria no. 353-A/2013 that defines the indoor air limit values for the pollutants $\mathrm{PM}_{10}, \mathrm{PM}_{2.5}$, $\mathrm{CO}_{2}$, CO and VOC. CO never exceeded the limit value of $10 \mathrm{mg} / \mathrm{m}^{3}$. For all the other pollutants, the Portuguese IAQ limit concentrations were sometimes exceeded. VOC exceeded the reference value of $0.6 \mathrm{mg} / \mathrm{m}^{3}$ in both classes. This pollutant is emitted by consumer products or 
structures that exist in the indoor environments, such as carpeting, furniture cleaners, paints, perfumes, lacquers and solvents (Almeida-Silva et al. 2014c). For $\mathrm{PM}_{10}, \mathrm{PM}_{2.5}$ and $\mathrm{CO}_{2}$ the maximum value exceeds the guidelines only in the aerobic classes. These higher concentrations during aerobic classes were expected since $\mathrm{CO}_{2}$ concentration is a function of the site occupation, ventilation rates and metabolic activity of the occupants (Ramos et al, 2014; Pegas et al., 2011) and particles are highly dependent on the activity pattern of the room that can promote resuspension of particles (Canha et al., 2010, 2012; Braniš and Safranek, 2011).

$\mathrm{CH}_{2} \mathrm{O}$ and $\mathrm{O}_{3}$ were only measured in aerobic classes due to failing in the equipment. In the aerobic classes, $\mathrm{CH}_{2} \mathrm{O}$ showed the maximum value $\left(0.25 \mathrm{mg} / \mathrm{m}^{3}\right)$ which is above the guideline. $\mathrm{CH}_{2} \mathrm{O}$ is a VOC, but given its importance due to the related health effects, is usually assessed in an individualized form. However, its indoor sources are also similar to the sources of VOC. $\mathrm{O}_{3}$ is not regulated by the Portuguese legislation.

Table 3

\subsection{Estimation of inhaled dose}

The inhaled dose was calculated by using the VÉ estimated for men and women (Table 2) and the air pollutants' concentrations measured during the fitness classes (Table 3). Table 4 presents the estimated inhaled dose discriminated by gender and type of activity considering the minimum, mean and the maximum pollutant concentrations measured during the classes.

Higher inhalation doses were determined for the aerobic classes as a consequence of the high Table 4 VE associated with this activity. For men, the average aerobic/holistic ratio of the inhaled dose was 1.4 (maximum ratios calculated for $\mathrm{PM}_{10}$ and $\mathrm{CO}$ with values equal to 4.0 and 3.9, respectively) while for women the average aerobic/holistic ratio was 1.8 (maximum ratios calculated for $\mathrm{PM}_{10}$ and $\mathrm{CO}$ with the values 5.1 and 5.0, respectively).

The average ratio (women/men) of 1.5 was obtained for inhaled doses, meaning that women inhales 1.5 times higher doses than men.

These results points to the importance of studying the specific VÉ associated with each activity and gender in the calculation of the inhaled dose.

\section{DISCUSSION}

Assessing the inhaled dose of air pollutants in fitness centers is the key determinant of the impacts that these pollutants can have on the health of the sport practitioners. Differences between VE் and pollutant concentrations between different classrooms influence the inhaled dose of air pollution and therefore an accurate assessment of these two parameters is fundamental. 
Until now VE் has never been measured for different fitness class users. The measurement of VE during fitness activity has two principal limitations: 1) the number of volunteers that have to use uncomfortable equipment/mask during a fitness class and 2) the influence that the use of this mask can have on the VE். Therefore, on large studies, it could be efficient to use an established relation between $\mathrm{HR}$ and $\mathrm{VE}$ for a sample of individuals and to apply the regression coefficients in field studies where HR can be easily measured by a heart rate monitor.

In this work 20 volunteers performed an incremental test on the treadmill in order to establish the individual relation between HR and VE during the exercise. This test showed that HR and VÉ are highly correlated as has also been reported before (Zuurbier et al., 2009). HR is not only influenced by exercise, but also by coffee, drugs, time of the day and temperature. These factors probably did not play an important role in this study. Differences in regression equations were observed between genders. According to Harms (2006), the reproductive hormones estrogen and progesterone can influence ventilation and pulmonary function during exercise. This author suggests that during heavy exercise, women demonstrate greater expiratory flow limitation and an increased effort to breath.

Figure 4 shows that VE் varied during the classes and between classes. In aerobic classes VE levels $(55 \mathrm{~L} / \mathrm{min})$ were on average 2.1 times higher than in holistic classes $(26 \mathrm{~L} / \mathrm{min})$.

IAQ also varies according to the characteristics of each fitness center such as ventilation system, occupancy, maintenance, age, etc. However, even in the same fitness classroom the pollutant concentrations can also vary according to the type of activity that is performed inside it. Figure 4 shows that $\mathrm{PM}_{10}$ concentrations measured in the same classroom and on the same day were higher during the aerobic class (average $45 \mu \mathrm{g} / \mathrm{m}^{3}$ ) than in the holistic class (average $33 \mu \mathrm{g} / \mathrm{m}^{3}$ ) due to the greater resuspension caused by the first activity. Ramos et al. (2014) found that in studios, higher PM concentrations coincided with the period of fitness classes, revealing a relation between PM concentration and the resuspension of dust caused by the practitioners of physical activity. The same behaviour can be observed for $\mathrm{CO}_{2}$, found to be highly produced in an aerobic classes (Ramos et al., 2014).

Studies evaluating the inhaled dose of pollutants during exercise and physical activity are very scarce. As far as we know, this parameter has only been assessed for cyclists during commuting. For cyclists, Nyhan et al. (2014) calculate inhaled doses of $0.95 \mu \mathrm{g} / \mathrm{kg}$ for $\mathrm{PM}_{2.5}$ and $1.2 \mu \mathrm{g} / \mathrm{kg}$ for $\mathrm{PM}_{10}$. Panis et al. (2010) calculated average inhaled doses of $0.93 \mu \mathrm{g} / \mathrm{kg}$ for $\mathrm{PM}_{2.5}$ and 2.1 $\mu \mathrm{g} / \mathrm{kg}$ for $\mathrm{PM}_{10}$ (values adapted to the body weight of the present study and for 45 minutes in order to allow comparisons). These values are comparable with the dose estimated in our study for aerobic $\left(0.30 \mu \mathrm{g} / \mathrm{kg}\right.$ for $\mathrm{PM}_{2.5}$ and $1.2 \mu \mathrm{g} / \mathrm{kg}$ for $\left.\mathrm{PM}_{10}\right)$. 
Inhalation of air pollutants is influenced by VE், but deposition in lungs of air pollutants is also influenced by the amount of nasal and oral breathing and by the depth of inhalation (Zuurbier et al., 2009). More oral breathing and deeper inhalation occur during exercise in fitness classes, both leading to higher deposition of pollutants in lungs. In the present study, we have not been able to measure oral and nasal breathing separately, nor have we measured the depth of inhalation.

Besides the inhaled dose, it is important to consider the uptake fraction of pollutants. The solubility of the gaseous pollutants determines the absorption and the diffusion rates and particle size influence deposition fraction in the lungs (Bigazzi and Figliozzi, 2014). Smaller particles enhanced the deposition and hygroscopic aerosols will absorb water vapor from the lungs, thus growing in size and consequently changing their deposition properties (Winkler-Heil et al., 2014). Some of the analyzed pollutants have chemical characteristics that pose some concerns, individually or in synergistic actions. In a study conducted by Mautz (2003) it was found that $\mathrm{O}_{3}$ is capable to boost $\mathrm{CH}_{2} \mathrm{O}$ damage, therefore the inhaled estimated dose in this study for these pollutants was low $(2 \mu \mathrm{g} / \mathrm{kg})$, it is important to take into account the combined effects. $\mathrm{CH}_{2} \mathrm{O}$ is a highly soluble gas that may be absorbed in the upper respiratory tract at resting VE் values and $\mathrm{O}_{3}$ is an insoluble gas, which penetrate deep into the lungs with the main cellular target the terminal bronchioles and proximal alveoli. Its uptake is amplified for higher tidal volumes (volume of air in the lungs in one breath, L) than in breathing frequency (number of breaths per minute, breaths/min) (Mautz, 2003), thus even differences in the respiratory pattern cause different uptake dose.

$\mathrm{CO}_{2}$ was the gas that presented the higher inhaled dose but this pollutant is a human product of respiration. Studies showed that inhalation of high concentrations of $\mathrm{CO}_{2}\left(50000 \mathrm{mg} / \mathrm{m}^{3}\right)$ during physical activity has no effect on psychomotor performance (Vercruyssen et al., 2007).

\section{CONCLUSIONS}

Study the dose is a complex challenge. The inhaled dose is affected by several physiological and chemical mechanisms. Also the differences in the definitions used among the researchers lead to complex and tricky comparisons between the studies.

Knowing that trained or recreational athletes are at special risk when they are practicing exercise in polluted environments, this study assessed by the first time air pollutants' inhaled dose by users of fitness centers during the physical activity.

VÉ for different fitness classes were estimated based on the measurement of HR. Results generated within the present work can be used to calculate inhaled dose in future studies with a similar population. 
From the results we concluded that the magnitude of differences in pollutant concentrations depend not only on the fitness center, but also on the type of activity that occur inside the classrooms. During aerobic classes the concentrations of particles and $\mathrm{CO}_{2}$ were higher than in holistic classes. Also the VE் is higher during aerobic classes and consequently inhaled dose is on average 2.1 times higher in this activity compared with the holistic classes.

This study illustrates the importance of inclusion VE் data in comparing inhaled doses for different population groups.

The authors consider that sport activity in fitness centers have undeniable positive effects on the health of the sport practitioners. The results presented in this paper should be seen as an opportunity to improve environmental conditions in gymnasiums in order to potentiate their positive impacts.

\section{AKNOWLEDGMENTS}

The authors would like to acknowledge FCT for their PhD grants SFRH/BD/79277/2011 (C.A. Ramos), SFRH/BD/73022/2010 (T. Almeida) and post PhD grant SFRH/BPD/84315/2012 (J.F. Reis) and to all the participants in this study.

\section{REFERENCES}

Almeida SM, Freitas MC, Reis M, Pinheiro T, Felix PM, Pio CA. Fifteen years of nuclear techniques application to suspended particulate matter studies. J Radioanal Nucl Ch, 2013; 297:347-356.

Almeida-Silva M, Almeida SM, Gomes JF, Albuquerque PC, Wolterbeek HT. Determination of airborne nanoparticles in Elderly Care Centers. J Toxicol Env Heal A, 2014a; 77(14-16): 86778.

Almeida-Silva M, Almeida SM, Wolterbeek HT. Multi-elemental characterization of indoor aerosols in Elderly Care Centers. J Radioanal Nucl Ch, 2014b; 300:679-684.

Almeida-Silva M, Almeida SM, Pegas PN, Nunes T, Alves CA, Wolterbeek HT. Exposure and dose assessment to particles components among an elderly population. Atmos Environ, 2015; 102:156-166.

Almeida-Silva M, Wolterbeek HT, Almeida SM. Elderly exposure to indoor air pollutants. Atmos Environ, 2014c; 85:54-63.

Behrens G, Jochem C, Keimling M, Ricci C, Schmid D, et al. The association between physical activity and gastroesophageal cancer: systematic review and meta-analysis. Eur J Epidemiol, 2014; 29(3):151-170. 
Bigazzi AY and Figliozzi MA. Review of urban bicyclists' intake and uptake of traffic-related air pollution. Transport Rev, 2014; 34(2): 221-245.

Braniš M, Safranek J. Characterization of coarse particulate matter in school gym. Environ Res, 2011;111(4):485-91.

Brown R, Riddell M, Macpherson A, Canning K, Kuk J. All-cause and cardiovascular mortality risk in U.S. adults with and without type 2 diabetes: influence of physical activity, pharmacological treatment and glycemic control. J Diabetes Complicat, 2014; 28(3):311-315.

Buffart LM, Singh AS, van Loon E, Vermeulen HI, Brug J, et al. Physical activity and the risk of developing lung cancer among smokers: a meta-analysis. J Sci Med Sport, 2014; 17 (1):6771.

Buonanno G, Fuoco F, Marini S, Stabile L. Particle resuspension in school gyms during physical activities. Aerosol Air Qual Res, 2013; 12:803-813.

Canha N, Almeida M, Freitas MC, Almeida SM. Seasonal variation of total particulate matter and children respiratory diseases at lisbon basic schools using passive methods. Procedia Environmental Sciences, 2011;4:170-183.

Canha N, Almeida SM, Freitas MC, Wolterbeek HT, Cardoso J, Pio C, Caseiro A. Impact of wood burning on indoor PM2.5 in a primary school in rural Portugal. Atmos Environ, 2014; 94:663-670.

Canha N, Freitas MC, Almeida SM, Almeida M, Ribeiro M, Galinha C et al. Indoor school environment: easy and low cost to assess inorganic pollutants. J Radioanal Nucl Ch, 2010; 286(2):495-500.

Canha N, Martinho M, Almeida-Silva M, Freitas MC, Almeida SM, Pegas P, et al. Indoor air quality in primary schools. Int J Environ Pollut, 2012; (1/2/3/4):396-410.

Carlisle AJ, Sharp NCC. Exercise and outdoor ambient air pollution. Brit J Sport Med, 2001; $35: 214-222$.

Dons E, Panis LI, Poppel MV, Theunis J, Willems, Torfs R, et al. Impact of time-activity patterns on personal exposure to black carbon. Atmos Environ, 2011; 45(21): 3594-3602Duda JL, Williams GC, Ntoumanis N, Daley A, Eves FF, et al. Effects of a standard provision versus an autonomy supportive exercise referral programme on physical activity, quality of life and well-being indicators: a cluster randomised controlled trial. Int J Behav Nutr Phyl, 2014; 11:10. 
European Comission. Eurobarometer Sport and Physical Activity Report, 2014. http://ec.europa.eu/public_opinion/archives/ebs/ebs_412_en.pdf

Foster C, Florhaug J, Franklin J, Gottschall L, Hrovatin L, Parker S, et al. New approach to monitoring exercise training. J Strength Cond Res, 2001; 15(1):109-115.

Foucaut AM, Berthouze-Aranda SE, Touillaud M, Kempf-Lepine AS, Baudinet C, et al. Reduction of health risk factors through an adapted physicalactivity program in patients with breast cancer. Support Care Cancer, 2014; 22(4):1097-1104.

Gonçalves AK, Florencio G, Silva M, Cobucci R, Giraldo PC, et al. Effects of physical activity on breast cancer prevention: a systematic review. JPAH, 2014; 11(2):445454.

Gotte M, Kesting S, Winter C, Rosenbaum D, Boos J. Comparison of selfreported physical activity in children and adolescents before and during cancer treatment. Pediatr Blood Cancer, 2013; 61(6):1023-1028.

Harms CA. Does gender affect pulmonary function and exercise capacity? Resp Physiol Neurobi, 2006; 151(2-3):124-131.

Holmberg S, Li Y. Modeling of the indoor environment - Particle dispersion and deposition. Indoor Air, 1998; 8:113-122.

Jin H, He C, Lu L, Fan J. Numerical investigation of the wall effect on airborne particle dispersion in a test chamber. Aerosol Air Qual Res, 2013; 13:786-794.

Keimling M, Behrens G, Schmid D, Jochem C, Leitzmann MF. The association between physical activity and bladder cancer: systematic review and meta-analysis. Br J Cancer, 2014;110(7):1862-1870.

Laskowski ER, Lexell J. Exercise and sports for health promotion, disease, and disability. PM\&R, 2012; 4:795-796.

Mautz WJ. Exercising animal models in inhalation toxicology: interactions with ozone and formaldehyde. Environ Res, 2003; 92:14-26.

Mermier CM, Samet JM, Lambert WE, Chick TW. Evaluation of the relationship between heart rate and ventilation for epidemiological studies. Arch Environ Health, 1993; 48(4):263-269.

Myers J. Exercise and cardiovascular health. Circulation, 2003;107(e2-e5). 
Nyhan M, McNabola A, Misstear B. Comparison of particulate matter dose and acute heart rate variability response in cyclists, pedestrians, bus and train passengers. Sci Tot Environ, 2014; 468-469:821-831.

Panis LI, Geus B, Vandenbulcke G, Willems H, Degraeuwe B, Bleux N, et al. Exposure to particulate matter in traffic: a comparison of cyclists and car passengers. Atmos Environ, 2010; 44:2263-2270.

Patel K, Sui XM, Zhang Y, Fonarow GC, Aban IB, et al. Prevention of heart failure in older adults may require higher levels of physical activity than needed for other cardiovascular events. Int J Cardiol, 2013; 168(3):1905-1909.

Pegas PN, Alves CA, Evtyugina MG, Nunes T, Cerqueira M, Franchi M, et al. Indoor air quality in elementary schools of Lisbon in Spring. Environ Geochem Hlth, 2011; 33:455-468.

Pegas PN, Evtyugina MG, Alves CA, Nunes T, Cerqueira M, Franchi M, et al. Outdoor/indoor air quality in primary schools in Lisbon: a preliminary study. Quimica Nova, 2010; 33:11451149.

Pila E, Stamiris A, Castonguay A, Sabiston CM. Body-related envy: a social comparison perspective in sport and exercise. J Sport Exercise Psy, 2014; 36(1):93-106.

Ramos CA, Wolterbeek HT, Almeida SM. Exposure to indoor air pollutants during physical activity in fitness centers. Build Environ, 2014; 82:349-360.

Ramos CA, Viegas C, Cabo Verde S, Wolterbeek HT, Almeida SM. Assessment of fungal and bacterial load in fitness centers. Indoor and Built Environment [in press], 2015.

Vercruyssen M, Kamon E, Hancock PA. Effects of carbon dioxide inhalation on psychomotor and mental performance during exercise and recovery. Int J Occup Saf Ergo, 2007; 13(1):15-27.

Viegas C, Almeida-Silva M, Gomes AQ, Wolterbeek HT, Almeida SM. Fungal contamination assessment in portuguese elderly care center. J Toxicol Env Heal A, 2014; 77(1-3):14-23.

Weisser B. Physical activity and exercise in type 2 diabetes. Diabetologe, 2014; 10(2):108.

WHO. Physical activity - Fact sheet n. ${ }^{\circ}$ 385. Obtained in August 2014: http://www.who.int/mediacentre/factsheets/fs385/en/

WHO. Review of physical activity surveillance data sources in European Union Member States, Report no.6. World Health Organization, Copenhagen, Denmark. 
Warburton D, Nicol C, Bredin S. Health benefits of physical activity: the evidence. CMAJ, 2006; 176(6): 801-809.

Winkler-Heil R, Ferron G, Hofmann W. Calculation of hygroscopic particle deposition in the human lung. Inhal Toxicol, 2014; 26 (3):193-206.

Zuurbier M, Hoek G, van den Hazel P, Brunekreef B. Minute ventilation of cyclists, car and bus passengers: an experimental study. Environ Health-Glob, 2009; 48(8).

\section{Figures Caption}

Figure 1. Diagram of the methodology (BW - body mass in $\mathrm{kg} ; \mathrm{t}$ - duration of the fitness class)

Figure 2. Individual fitted regression lines of HR (beats per minute) and VE் (litre per minute) discriminated by men and women.

Figure 3. Box plot of the heart rate of the individuals (men and women) in the fitness classes (holistic and aerobic) and average values in the groups.

Figure 4. VE and $\mathrm{PM}_{10}$ concentration and inhaled dose during holistic (a and b) and aerobic (c e d) fitness classes, for men and women. The grey area represents the total inhaled dose of $\mathrm{PM}_{10}$. 
Figure 1

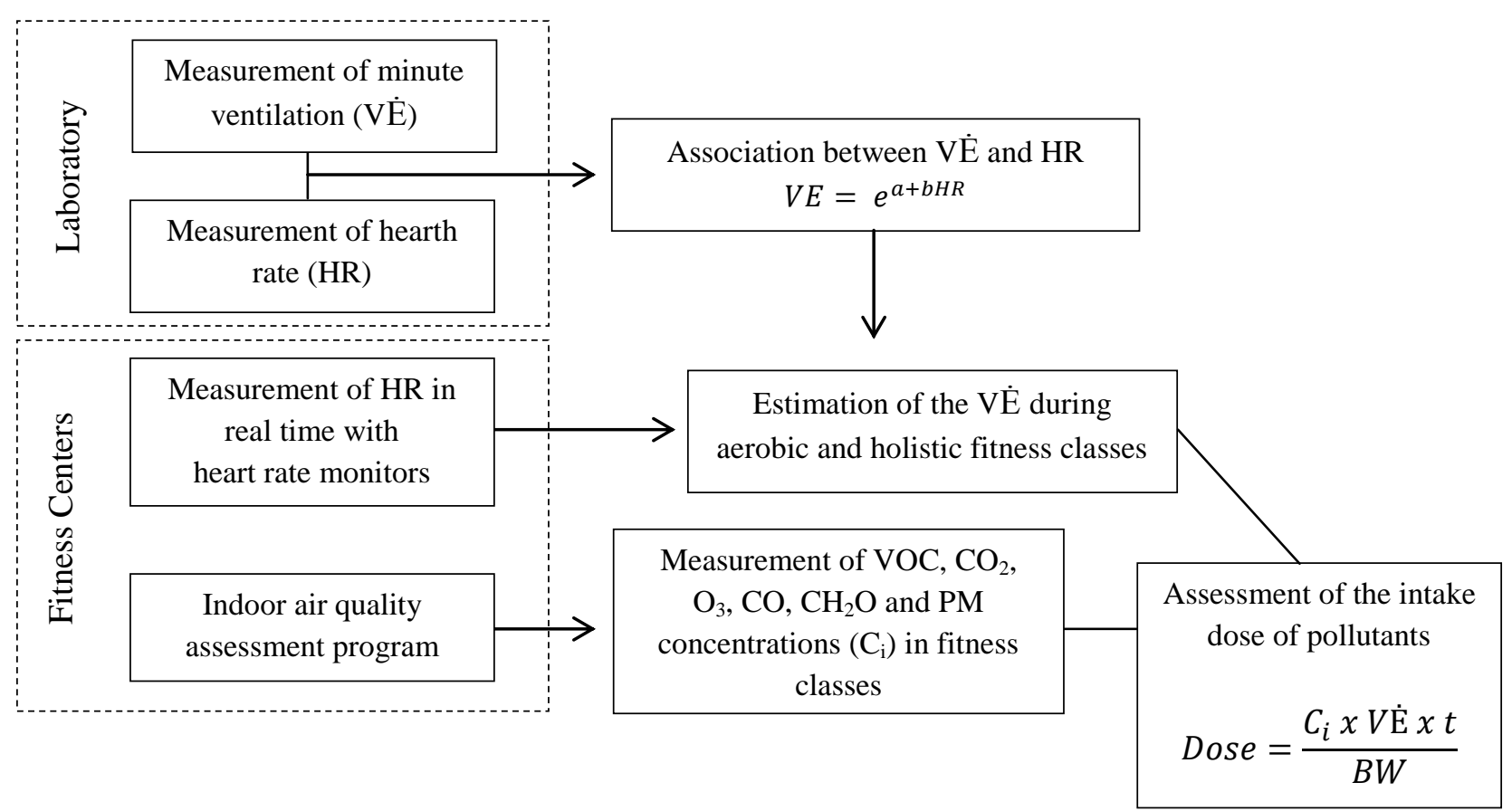


Figure 2

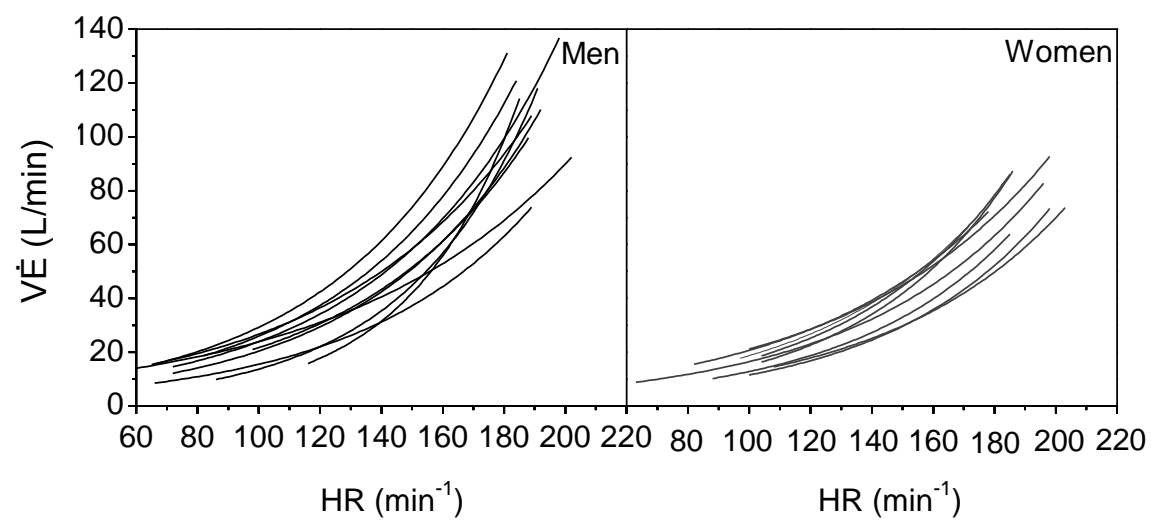


Figure 3

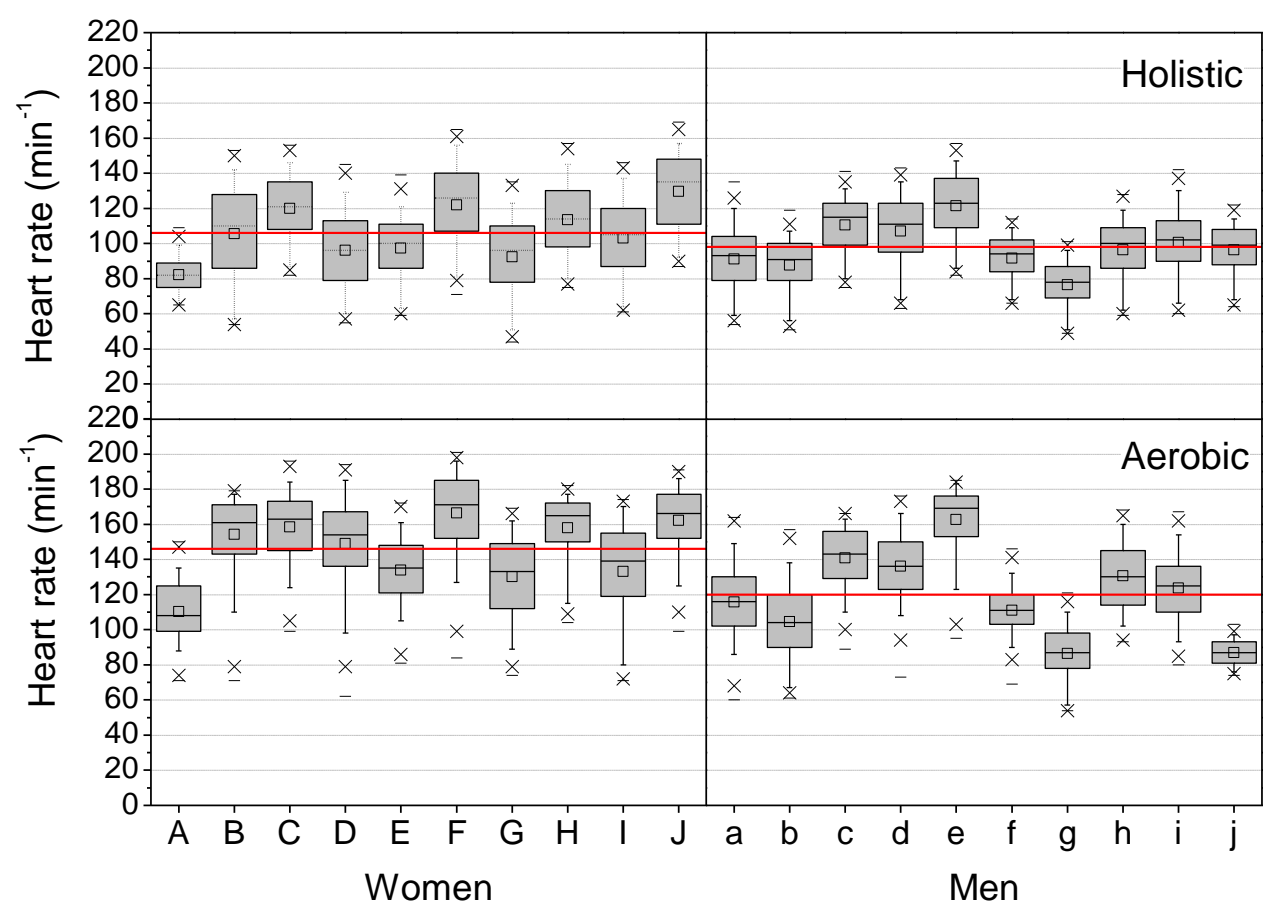


Figure 4

a)

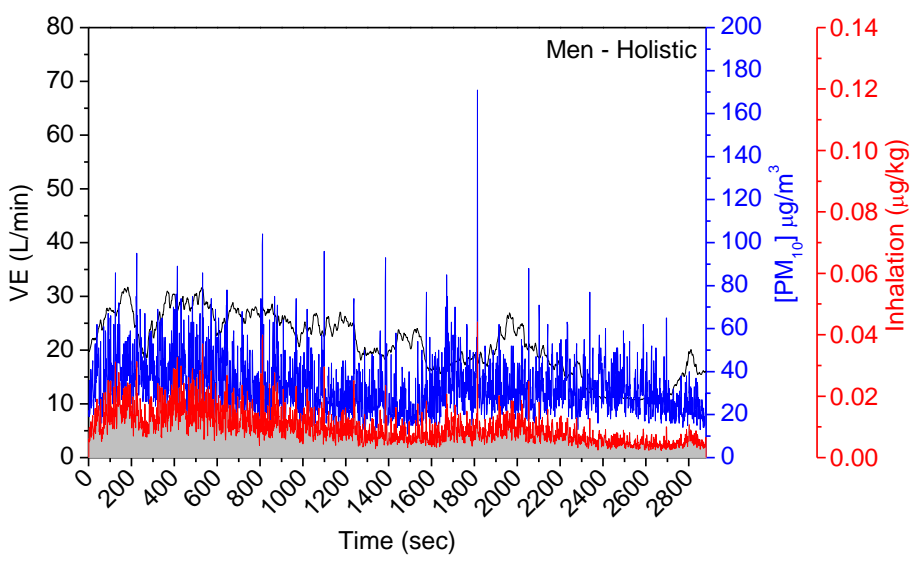

c)

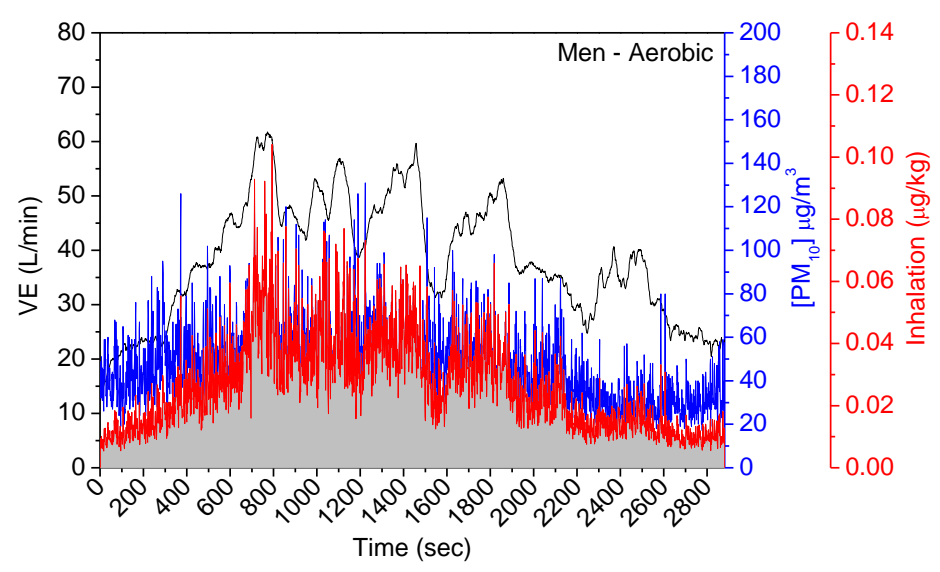

b)

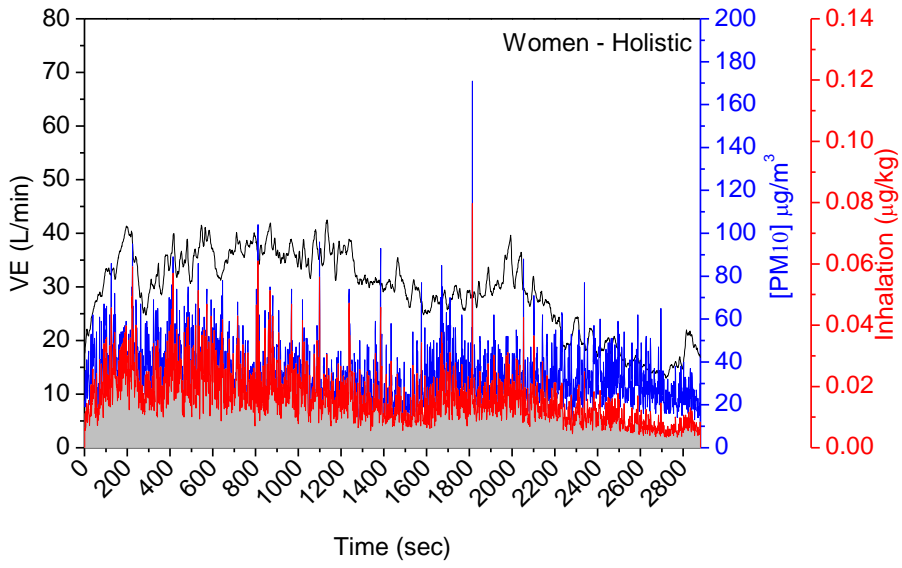

d)

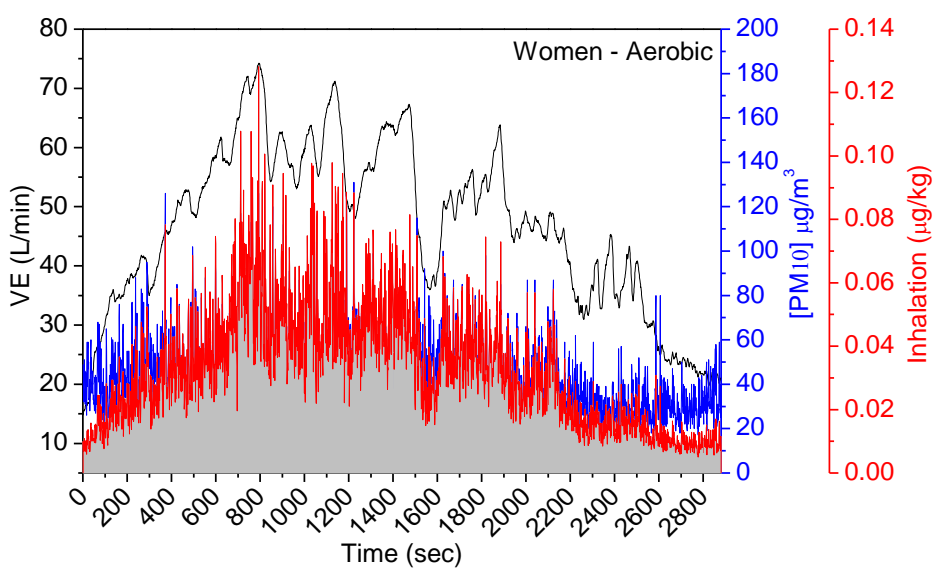


Table 1. Descriptive statistics of the participants

\begin{tabular}{|c|c|c|}
\hline & $\operatorname{Men}(n=10)$ & Women $(\mathrm{n}=10)$ \\
\hline \multicolumn{3}{|l|}{ Age (years) } \\
\hline & $24(18-29)$ & $28(23-38)$ \\
\hline \multicolumn{3}{|l|}{$\bar{x}$ (range) } \\
\hline & $<1 \mathrm{~h}-20 \%$ & $<1 \mathrm{~h}-20 \%$ \\
\hline Physical Activity & $1 \mathrm{~h}-3 \mathrm{~h}-20 \%$ & $1 h-3 h-40 \%$ \\
\hline \multirow[t]{2}{*}{ (hr/week) } & $3 h-6 h-40 \%$ & $3 h-6 h-20 \%$ \\
\hline & $>6 h-20 \%$ & $>6 \mathrm{~h}-20 \%$ \\
\hline \multicolumn{3}{|l|}{ BMI $\left(\mathrm{kg} / \mathrm{m}^{2}\right)$} \\
\hline $\bar{x}$ (range) & $24(18-27)$ & $22(20-27)$ \\
\hline \multicolumn{3}{|l|}{ Weight (kg) } \\
\hline & $73(48-85)$ & $61(59-75)$ \\
\hline $\bar{x}$ (range) & & \\
\hline
\end{tabular}


Table 2. Collected data and results of the estimation of minute ventilation

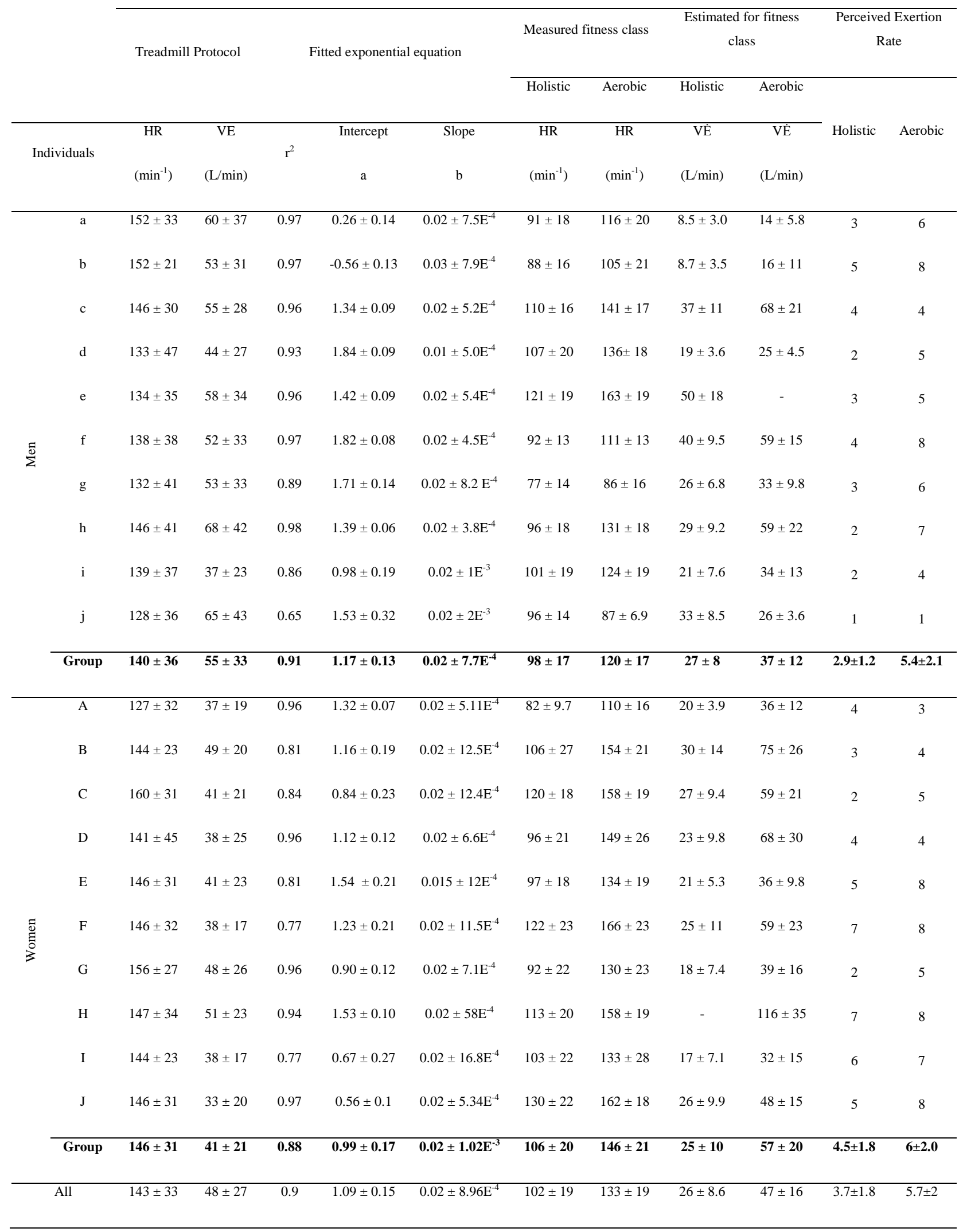


Table 3. Statistical data of IAQ pollutants measured during different types of fitness classes

\begin{tabular}{|c|c|c|c|c|c|c|c|c|c|c|c|}
\hline Pollutant & Class & $\mathrm{n}$ & Mean \pm stdev & $\min$ & $\mathrm{P}_{5}$ & $\mathrm{P}_{25}$ & $\mathrm{P}_{50}$ & $\mathrm{P}_{75}$ & $\mathrm{P}_{95}$ & Max & $\begin{array}{c}\text { IAQ } \\
\text { Guidelines* }\end{array}$ \\
\hline \multirow{2}{*}{$\begin{array}{c}\text { tVOC } \\
\left(\mathrm{mg} / \mathrm{m}^{3}\right)\end{array}$} & Aerobic & 45 & $0.48 \pm 0.42$ & 0.010 & 0.050 & 0.17 & 0.46 & 0.66 & 1.1 & 2.5 & \multirow{2}{*}{0.6} \\
\hline & Holistic & 5 & $0.38 \pm 0.23$ & 0.16 & 0.17 & 0.18 & 0.31 & 0.37 & 0.85 & 0.85 & \\
\hline \multirow{2}{*}{$\begin{array}{c}\mathrm{CH}_{2} \mathrm{O} \\
\left(\mathrm{mg} / \mathrm{m}^{3}\right)\end{array}$} & Aerobic & 13 & $0.07 \pm 0.06$ & 0.010 & 0.010 & 0.038 & 0.050 & 0.075 & 0.19 & 0.25 & \multirow{2}{*}{0.1} \\
\hline & Holistic & 0 & - & - & - & - & - & - & - & - & \\
\hline \multirow{2}{*}{$\begin{array}{c}\mathrm{CO}_{2} \\
\left(\mathrm{mg} / \mathrm{m}^{3}\right)\end{array}$} & Aerobic & 45 & $1682 \pm 599$ & 208 & 984 & 1327 & 1582 & 1815 & 2846 & 5964 & \multirow{2}{*}{2250} \\
\hline & Holistic & 5 & $1662 \pm 376$ & 831 & 986 & 1522 & 1738 & 1878 & 2173 & 2406 & \\
\hline \multirow{2}{*}{$\begin{array}{c}\mathrm{O}_{3} \\
\left(\mathrm{mg} / \mathrm{m}^{3}\right)\end{array}$} & Aerobic & 13 & $0.01 \pm 0.054$ & 0.005 & 0.005 & 0.005 & 0.005 & 0.005 & 0.020 & 1.9 & \multirow[b]{2}{*}{-} \\
\hline & Holistic & 0 & - & - & - & - & - & - & - & - & \\
\hline \multirow{2}{*}{$\begin{array}{c}\mathrm{CO} \\
\left(\mathrm{mg} / \mathrm{m}^{3}\right)\end{array}$} & Aerobic & 41 & $0.64 \pm 0.49$ & 0.005 & 0.12 & 0.30 & 0.57 & 0.83 & 1.6 & 2.7 & \multirow{2}{*}{10} \\
\hline & Holistic & 5 & $0.29 \pm 0.12$ & 0.12 & 0.12 & 0.23 & 0.23 & 0.34 & 0.6 & 0.69 & \\
\hline \multirow{2}{*}{$\begin{array}{c}\mathrm{PM}_{0.5} \\
\left(\mu \mathrm{g} / \mathrm{m}^{3}\right)\end{array}$} & Aerobic & 45 & $2.9 \pm 1.7$ & 0.52 & 0.76 & 1.6 & 2.6 & 4.02 & 6.2 & 9.3 & \multirow[b]{2}{*}{-} \\
\hline & Holistic & 5 & $2.4 \pm 0.86$ & 1.6 & 1.7 & 1.9 & 1.9 & 2.4 & 4.3 & 4.4 & \\
\hline \multirow{2}{*}{$\begin{array}{c}\mathrm{PM}_{1} \\
\left(\mu \mathrm{g} / \mathrm{m}^{3}\right)\end{array}$} & Aerobic & 45 & $4.6 \pm 2.5$ & 0.700 & 1.5 & 2.9 & 4.3 & 5.7 & 9.8 & 15 & \multirow[b]{2}{*}{-} \\
\hline & Holistic & 5 & $3.6 \pm 1.3$ & 2.9 & 2.8 & 2.9 & 3.03 & 3.8 & 6.5 & 6.9 & \\
\hline \multirow{2}{*}{$\begin{array}{c}\mathrm{PM}_{2.5} \\
\left(\mu \mathrm{g} / \mathrm{m}^{3}\right) \\
\end{array}$} & Aerobic & 45 & $8.3 \pm 4.5$ & 0.89 & 2.5 & 5.4 & 7.3 & 10 & 16 & 34 & \multirow{2}{*}{25} \\
\hline & Holistic & 5 & $5.5 \pm 2.2$ & 3.5 & 3.9 & 4.1 & 4.4 & 5.6 & 11 & 12 & \\
\hline \multirow{2}{*}{$\begin{array}{c}\mathrm{PM}_{5} \\
\left(\mu \mathrm{g} / \mathrm{m}^{3}\right)\end{array}$} & Aerobic & 45 & $18 \pm 10$ & 1.4 & 4.9 & 10 & 15 & 23 & 38 & 89 & \multirow[b]{2}{*}{-} \\
\hline & Holistic & 5 & $10 \pm 6.3$ & 4.2 & 5 & 5.9 & 7 & 9.2 & 26 & 30 & \\
\hline \multirow{2}{*}{$\begin{array}{c}\mathrm{PM}_{10} \\
\left(\mu \mathrm{g} / \mathrm{m}^{3}\right)\end{array}$} & Aerobic & 45 & $31 \pm 23$ & 1.8 & 7.9 & 16 & 24 & 40 & 76 & 153 & \multirow{2}{*}{50} \\
\hline & Holistic & 5 & $14 \pm 8.9$ & 4.2 & 6.2 & 7.9 & 10 & 15 & 36 & 42 & \\
\hline
\end{tabular}


Table 4. Estimated inhaled dose of pollutants in holistic and aerobic class

\begin{tabular}{cccccc}
\hline \multicolumn{1}{c}{ Men } & \multicolumn{3}{c}{ Women } \\
\hline $\min$ & Mean & Max & min & Mean & Max \\
$(\mu \mathrm{g} / \mathrm{kg})$ & $(\mu \mathrm{g} / \mathrm{kg})$ & $(\mu \mathrm{g} / \mathrm{kg})$ & $(\mu \mathrm{g} / \mathrm{kg})$ & $(\mu \mathrm{g} / \mathrm{kg})$ & $(\mu \mathrm{g} / \mathrm{kg})$
\end{tabular}

\begin{tabular}{|c|c|c|c|c|c|c|}
\hline & \multicolumn{6}{|c|}{ Holistic } \\
\hline tVOC & 2.7 & 6.3 & 14 & 3.1 & 7.2 & 16 \\
\hline $\mathrm{CO}_{2}$ & 13838 & 27670 & 40046 & 15947 & 31887 & 46149 \\
\hline $\mathrm{O}_{3}$ & 0.00 & - & 0.00 & 0.00 & - & 0.00 \\
\hline $\mathrm{CO}$ & 1.9 & 4.8 & 11 & 2.2 & 5.6 & 13 \\
\hline $\mathrm{CH}_{2} \mathrm{O}$ & 0.000 & - & 0.000 & 0.000 & - & 0.000 \\
\hline $\mathrm{PM}_{0.5}$ & 0.027 & 0.040 & 0.074 & 0.031 & 0.046 & 0.085 \\
\hline $\mathrm{PM}_{1.0}$ & 0.043 & 0.062 & 0.12 & 0.050 & 0.071 & 0.13 \\
\hline $\mathrm{PM}_{2.5}$ & 0.057 & 0.091 & 0.202 & 0.066 & 0.105 & 0.23 \\
\hline $\mathrm{PM}_{5.0}$ & 0.070 & 0.16 & 0.49 & 0.081 & 0.18 & 0.57 \\
\hline \multirow[t]{2}{*}{$\mathrm{PM}_{10}$} & 0.070 & 0.23 & 0.70 & 0.081 & 0.26 & 0.81 \\
\hline & \multicolumn{6}{|c|}{ Aerobic } \\
\hline tVOC & 0.29 & 14 & 74 & 0.44 & 21 & 108 \\
\hline $\mathrm{CO}_{2}$ & 6166 & 49787 & 176469 & 9070 & 73235 & 259580 \\
\hline $\mathrm{O}_{3}$ & 0.304 & 1.6 & - & 0.45 & 2.4 & - \\
\hline $\mathrm{CO}$ & 0.00 & 19 & 80 & 0.000 & 28 & 117.516 \\
\hline $\mathrm{CH}_{2} \mathrm{O}$ & 0.29 & 2.0 & 7.4 & 0.44 & 2.975 & 11 \\
\hline $\mathrm{PM}_{0.5}$ & 0.015 & 0.086 & 0.28 & 0.023 & 0.13 & 0.41 \\
\hline $\mathrm{PM}_{1.0}$ & 0.021 & 0.14 & 0.45 & 0.030 & 0.20 & 0.66 \\
\hline $\mathrm{PM}_{2.5}$ & 0.026 & 0.24 & 1.0 & 0.039 & 0.36 & 1.5 \\
\hline $\mathrm{PM}_{5.0}$ & 0.043 & 0.53 & 2.6 & 0.063 & 0.77 & 3.9 \\
\hline $\mathrm{PM}_{10}$ & 0.052 & 0.92 & 4.5 & 0.077 & 1.4 & 6.7 \\
\hline
\end{tabular}

